\section{Embryonale Stammzellen: Handeln in Grenzen}

\begin{abstract}
Bis vor wenigen Jahren waren menschliche embryonale Stammzellen nur "Insidern" ein Begriff. Dies änderte sich 1998 schlagartig, als es gelang, solche Stammzellen in Kultur zu züchten. Seither vergeht kaum ein Tag, an dem das Thema nicht von den Medien aufgegriffen wird: Neue, zum Teil spektakuläre Forschungserkenntnisse, ethische Aspekte, Hoffnungen und Befürchtungen werden nun auch in der Schweiz zumindest medial diskutiert. Auch aufder politischen Bühne hat sich seit dem Entscheid des Nationalfonds im September 2001, den Import von menschlichen embryonalen Stammzellen zu Forschungszwecken zuzulassen, einiges bewegt. So soll ein sogenanntes "kleines Gesetz", welches die Forschung an menschlichen Embryonen regelt und dem in Vorbereitung begriffenen Gesetz "Forschung am Menschen" vorgezogen wird, bereits im Frühsommer in Vernehmlassung gehen.

Die Zentrale Ethikkommission der SAMW hat im letzten Jahr aufgrund intensiver Diskussionen und Expertenanhörungen ein Positionspapier verfasst, welches in dieser Ausgabe publiziert wird. Die SAMW befürwortet die Verwendung von sogenannt «überzähligen
\end{abstract}

Embryonen aus In-vitro-Fertilisationen", spricht sich hingegen klar gegen die Herstellung von Embryonen eigens zu Forschungszwecken aus. Ebenso distanziert sie sich beim heutigen Stand des Wissens vom "therapeutischen Klonieren".

Ihre befürwortende Haltung zur Forschung an "überzähligen Embryonen" beruht vor allem auf dem enormen Potential, welches diese Zellen erahnen lassen. Es besteht Hoffnung, in absehbarer Zeit neuartige Therapien für eine Vielzahl von heute unheilbaren chronischen Krankheiten entwickeln zu können. Noch kann nicht abgeschätzt werden, wie weit sich diese Hoffnungen erfüllen werden, denn die Forschung steckt noch ganz in den Anfängen und es wird noch Jahre dauern, bis das grundlegende Wissen zur Entwicklung von wirksamen Therapien verfügbar sein wird.

Die SAMW warnt deshalb vor übertriebenen Heilsversprechungen, um die Glaubwürdigkeit der Forschung gegenüber der Gesellschaft nicht weiter zu gefährden. Zudem setzt sie sich ein für einen offenen und ehrlichen Dialog mit der Gesellschaft über Chancen, aber auch über Risiken und ethische Dilemmas.

Das Positionspapier soll dazu einen konstruktiven Beitrag liefern.

Prof. Werner Stauffacher, Präsident SAMW Dr. Margrit Leuthold, Generalsekretärin SAMW

\section{Cellules souches embryonnaires: agir sans tout permettre}

Il y a quelques années encore, seuls quelques initiés pouvaient se faire une idée sur les cellules souches embryonnaires humaines. En 1998 toutefois, avec la possibilité de cultiver ces cellules souches, cette situation changea très rapidement. Depuis, il ne se passe presque plus une journée sans que les médias n'abordent ce sujet: les nouvelles découvertes scientifiques parfois spectaculaires, les aspects éthiques, les espoirs et les craintes sont désormais aussi discutés dans les médias suisses. Egalement du côté politique, les choses ont bougé depuis la décision du Fonds National en septembre 2001, d'autoriser l'importation de cellules souches embryonnaires humaines à des fins de recherche. Ainsi, une "petite loi" réglementant la recherche sur les embryons humains et devançant la loi actuellement en projet sur "la recherche sur l'être humain" sera soumise à consultation dès le début de l'été prochain.

Après d'intenses discussions et de nombreuses auditions d'experts, la Commission Centrale d'Ethique de l'ASSM a rédigé une prise de position publiée dans le présent numéro. L'ASSM se déclare favorable à l'utili- sation d'uembryons surnuméraires constitués lors de la fécondation in vitro", mais s'oppose fermement à la production d'embryons à des fins de recherche. De même, au stade actuel des connaissances scientifiques, elle exprime de vives réserves quant au "clonage thérapeutique".

Sa position favorable $\dot{a}$ la recherche sur les "embryons surnuméraires" repose avant tout sur le potentiel énorme de ces cellules. En effet, celles-ci permettraient, dans un avenir plus ou moins proche, de développer de nouvelles thérapies pour le traitement de maladies chroniques actuellement encore incurables. On ne peut toutefois pas encore évaluer dans quelle mesure ces espoirs pourront se réaliser, la recherche étant toujours à ses débuts; il faudra sans doute encore des années pour que les connaissances de base aboutissent au développement de thérapies efficaces.

Afin de ne pas compromettre la crédibilité de la recherche aux yeux de la société, l'ASSM met en garde contre des promesses de guérison utopiques. De plus, elle met tout en ouvre pour engager un dialogue ouvert et loyal sur les chances, mais aussi sur les risques et le dilemme éthique. Sa prise de position y contribuera de façon constructive.

Prof. Werner Stauffacher, Président ASSM Dr Margrit Leuthold, Secrétaire générale ASSM 